modify the motor response of Daphnia (phototaxis) in the same way as it prevents the actinic dermal response in man subjected to sunshine.

As light source we used a low-pressure mercury vapour lamp. We tested typical antihistamine substances of well-known activity. They were: $\alpha$-benzhydrylether- $\beta$-piperidinoethane $(\mathrm{I})^{3}$, antihistamine activity tested on guinea pig intestine: $6 \cdot 3$ microgm.; 2-phenylbenzylaminoethyl-imidazolin (II) (Antistin-Ciba), 45 microgm.; $\alpha$-phenylamino- $\beta$ aminoethane (III) ${ }^{4}, 29 \mathrm{mgm}$. It was found that all these substances in small doses suppress the negative phototaxis of Daphnia ; in larger doses, they invert the phototaxis to positive. This influence is proportional to the concentration of antihistamine used. The minimal effective dose for the substance I is 2.5 microgm. per c.c. of medium $(M / 133,000)$.

This reaction seems to be a specific one; it was not possible to provoke it with organic acids (acetic, lactic), lactose, glycocol and sodium choleinicum. Only strychnine among organic substances shows the same influence as antihistamines on Daphnias. The mechanism of its action is clearly neurotropic. Further, it was found that the ratio of activity of three antihistamine substances in this Daphnia test was the same as in the test on the surviving intestine of the guinea pig. Therefore, it cannot be excluded that the actinic influence of ultra-violet light provokes the release of histamine in invertebrates as in man, although histamine itself, when added to the medium, did not influence Daphnia in any way.

Department of General Physiology, Otakar Poupa Charles University, Prague. Oct. 13.

${ }^{1}$ Blum, Amer. Chem. Soc. Monograph 85 (New York, 1941).

Tyson, J. Invest. Dermatol., 7, 209 (1946).

- Loew, Kaiser and Moore, J. Pharmacol. and Exp. Therap., 88, 120 (1945).

- Cheymol, Exp. Ann. Biochim. Med., 5 (1945).

- Clarke, J. Gen. Physiol., 16, 99 (1932).

\section{Histaminolytic Activity of a Copper Protein in Serum}

Ww have recently been studying the blue serum globulin described by Luetscher ${ }^{1}$, Pedersen ${ }^{2}$, Holmberg $^{3}$ and Cohn et al. ${ }^{4}$. We have found that it has a copper content of about 0.05 per cent. By denaturing with a mixture of ethyl alcohol and chloroform and fractionating the supernatant solution with ammonium sulphate, we have found a blue copper protein with a copper content of 0.36 per cent. It seems very probable that this substance is identical with the hæmocuprein of Mann and Keilin ${ }^{s}$, which thus might be an integral part of the blue globulin.

When a purified preparation of this globulin was added to plasma from a male subject so that the final copper concentration was about $700 \mathrm{\gamma} / 100 \mathrm{ml}$., the result was a 400 -fold increase in histaminolytic activity. The blue globulin thus seems to be a component of the histaminolytic enzyme system of plasma.

As is well known, the increase in serum copper during pregnancy runs parallel in time with the in. crease in histaminolytic activity of plasma. We have also shown that this increase in copper is to be found in the globulin fraction of plasma.
A more detailed report of these investigations will soon appear in the Acta Chemica Scandinavica.

Our thanks are due to the Obstetrical Clinic of the Hospital of Malmö for help with the determinations of the histaminolytical activity of our preparations.

Department of Clinical Chemistry,

C. G. HolmberG

C.-B. Laureli

Lund.

Oct. 27.

1 Luetscher, J. A., J. Clin. Invest., 19, 313 (1940). Pedersen, K. O., "Ultracentrifugal Studies on Serum and Serum

"Holmberg, C. G., Acta Physiol. Scand, 8, Fasc. 2-3 (1944).

- Cohn, E. J., Strong, L. E., Hughes, W. L., jun., Mulford, D. J., Ashworth, J. N., Melin, M., and Taylor, H. L., J. Amer. Chem. Soc., 68, 459 (1946).

s Mann, T., and Keilin, D., Proc. Roy. Soc., B, 126, 303 (1938).

\section{Specific and Non-specific Competition in Tubular Excretion}

A CONSIDERABLE number of aromatic acids are known to be excreted by the renal tubules. The chemical structure of these compounds shows much variety, and it does not seem easy to find any property common to them which is not also shared by substances not excreted by the tubules. However, in every case hitherto investigated, the tubular excretion of any anion is reversibly depressed by the presence of considerable amounts of other anions excreted by the tubules. This effect is usually demonstrated by the use of 'Diodrast' or hippuric acid as the depressing agent. The phenomenon is often regarded as an indication that the excretion of these compounds is effected by a common mechanism, -or by intimately linked mechanisms.

It has, however, in some cases been shown that the presence of large amounts of 'Diodrast' in the blood may also interfere with reabsorptive processes in the tubules. This circumstance has led to the division of the effects of 'Diodrast' into specific and nonspecific competition ${ }^{1}$.

It seems clear that the depression of tubular excretion by 'Diodrast' may be non-specific, as well as its effect on tubular reabsorption. Thus the foundation for the view that the excretion of anions by the tubules is determined by specific interaction is considerably weakened by the demonstration of non-specific competition. In order to gain some further information as to the specificity of the depression of tubular excretion, the influence of hippuric acid on the excretion of uric acid has been studied in the chicken.

The intravenous injection of 100-200 $\mathrm{mgm}$. hippuric acid causes the uric acid excretion in a hen to fall by 20-50 per cent for a short period (about ten minutes). Afterwards the uric acid excretion rises slightly above the original level for some time, but soon returns to it. This effect might be interpreted as the result of a diminution of the renal blood flow, possibly caused by the hippuric acid. However, the excretion of piperidine, which is also excreted by the tubules in the chicken, is not influenced in a consistent manner. This is evidence against an influence on the blood flow.

Similarly, the excretion of phenol red is depressed by the intravenous injection of uric acid. In this case the excretion of methylnicotinamide has been used to assess the constancy of the renal blood flow, which seems to be constant or slightly increased. 